\title{
Patient autonomy in chronic care: solving a paradox
}

\author{
This article was published in the following Dove Press journal: \\ Patient Preference and Adherence \\ II December 2013 \\ Number of times this article has been viewed
}

\section{Gérard Reach \\ Department of Endocrinology, Diabetes, and Metabolic Diseases, Avicenne Hospital AP-HP, and EA 34I2, CRNH-IdF, Paris I 3 University, Sorbonne Paris Cité, Bobigny, France}

Correspondence: Gérard Reach Service d'Endocrinologie, Diabétologie, Maladies Métaboliques, Hôpital Avicenne AP-HP, I25 Rue de Stalingrad, 93000 Bobigny, France

Tel +33 । 48955 I 58

Fax +33 | 48955560

Email gerard.reach@avc.aphp.fr
Abstract: The application of the principle of autonomy, which is considered a cornerstone of contemporary bioethics, is sometimes in obvious contradiction with the principle of beneficence. Indeed, it may happen in chronic care that the preferences of the health care provider (HCP), who is largely focused on the prevention of long term complications of diseases, differ from those, more present oriented, preferences of the patient. The aims of this narrative review are as follows: 1) to show that the exercise of autonomy by the patient is not always possible; 2) where the latter is not possible, to examine how, in the context of the autonomy principle, someone (a HCP) can decide what is good (a treatment) for someone else (a patient) without falling into paternalism. Actually this analysis leads to a paradox: not only is the principle of beneficence sometimes conflicting with the principle of autonomy, but physician's beneficence may enter into conflict with the mere respect of the patient; and 3) to propose a solution to this paradox by revisiting the very concepts of the autonomous person, patient education, and trust in the patient-physician relationship: this article provides an ethical definition of patient education.

Keywords: preference, autonomy, person, reflexivity, empathy, sympathy, patient education, trust, respect, care

\section{Introduction}

In 1979, Beauchamp and Childress, in their seminal book, "Principles of Biomedical Ethics", proposed to add to the two Hippocratic principles of beneficence and nonmaleficence ("primum non nocere") two new ethical principles: justice and autonomy. The introduction of the latter ethical principle (ie, autonomy) was contemporaneous with the introduction of patient education. In 1972, Miller and Goldstein showed that patient education resulted in a decrease in the rate of amputation and hospitalization due to ketoacidosis in diabetic patients. ${ }^{2}$ Within the same period, the concept of evidence based medicine was established, ${ }^{3}$ which was aimed at demonstrating the efficiency of new therapeutic approaches. This led to the publication of good practice guidelines that aimed at helping the HCP to decide what is good and bad for their patients, and therefore to apply the Hippocratic ethical principles of beneficence and nonmaleficence.

However, it may happen that the triangulation formed by these three inventions of contemporary medicine (Figure 1) creates a conflict. Indeed, the preferences of HCPs often differ from those of patients. First, it is not surprising that HCPs' concerns focus on the best health interest of the patient, while patients' priority may actually be elsewhere (family, work, cultural issues, and the like). Secondly, in chronic care, HCPs' concerns focus more on the long term complications of the disease while patients' preferences are often more present oriented. For instance, in diabetes care, 
$\begin{array}{ll}\text { Cochrane A, Effectiveness and Efficiency: } & \text { Miller LV, Goldstein J, More efficient care }\end{array}$ Random Reflections on Health Services, 1972 setting. N Engl J Med. 1972;286:1388-1391

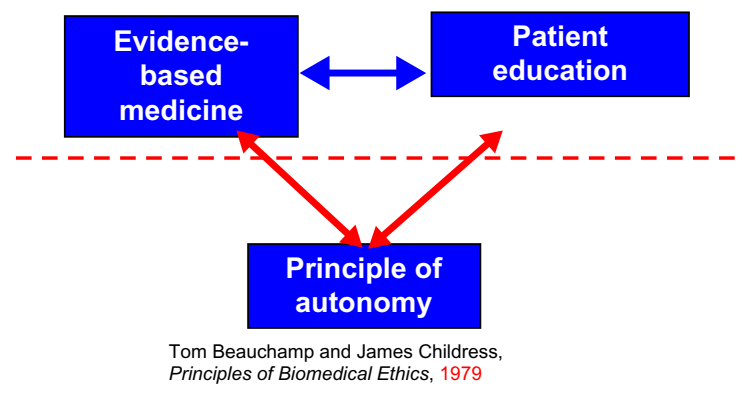

Figure I The three inventions of evidence based medicine, patient education, and autonomy.

Notes: The dotted line suggests that there may be a conflict between, on the one hand, evidence based medicine and patient education, and on the other hand, the introduction in medicine of the principle of autonomy. Note that the three inventions were done almost simultaneously.

HCPs' decisions are largely based on their desire to improve $\mathrm{HbA}_{1 \mathrm{c}}$ levels on the basis of current evidence, for instance the results of the Diabetes Control and Complications Trial (DCCT) trial in type 1 diabetes. ${ }^{4}$ By contrast, hypoglycemia is the complication that patients fear the most, ${ }^{5}$ and for this reason, they may be reluctant to intensify therapy according to the recommendations of the DCCT. ${ }^{6}$ These differences in the preferences of HCPs and patients can therefore result in patients' nonadherence (patients refusing on the basis of their preferences to follow medical prescriptions), ${ }^{7}$ and the HCP must recognize that they (ie, patients) are allowed to do this according to the new principle called autonomy.

Within this context, the structure of the arguments presented herein are as follows: 1) to show briefly that, actually, the exercise of autonomy by the patient is not always possible; 2) where autonomy is not possible, to determine how, within the framework of the autonomy principle, someone (a HCP) can decide on what is good (a treatment) for someone else (a patient) without falling into paternalism. We will show that this analysis leads to a paradox: not only is the principle of beneficence sometimes conflicting with the principle of autonomy, but physician's beneficence may enter into conflict with the mere respect of the patient; and 3) to show that the solution to this paradox can be found in the very definition of the autonomous person.

\section{Why the patient's exercise of autonomy is not always possible} A brief definition of autonomy

The etymology of the word "autonomy" supposes that patients are autonomous if they have the ability to decide themselves (autos) the laws (nomos) to which they comply, and if they have the possibility of applying those laws. Like an autonomous government exhibiting free control over its laws, the autonomous person expresses the will of maintaining control over her actions and denies any other person the possibility of control except if she gives the authorization. One can also say that the autonomous person has the capacity to decide to accomplish one action rather than another. Here, one switches from a conception of autonomy which concerns the person, to one which considers her actions.

Kant, who was at the origin of the "invention" of autonomy ${ }^{8}$ thought that human beings were autonomous, ie, under the control of the reason, and not heteronomous, ie, under the influence of passions:

Suppose some one asserts of his lustful appetite that, when the desired object and the opportunity are present, it is quite irresistible. Ask him - if a gallows were erected before the house where he finds this opportunity, in order that he should be hanged thereon immediately after the gratification of his lust, whether he could not then control his passion; we need not be long in doubt what he would reply. ${ }^{9}$

However, this example was only theoretical and given for the sake of pedagogy: we "ask" him, but give in advance our own, theoretical, answer. Actually, the mere existence of the phenomenon known as "weakness of will" contradicts Kant's prediction: in a number of circumstances, a number of people do not behave in an autonomous way and manifest a weakness of will. Like Saint Paul, they "do not do the good that they desire to practice, but they do the evil that they do not want to do". ${ }^{10}$ Indeed, they may come to regret it once it is done, and even before doing it, may know that they will later regret it. As philosopher, Gary Watson said, "when one acts weakly, one wants to some degree to do what one judges best. Weakness of will is marked by conflict and regret."11

These concepts are relevant for the analysis of autonomy in the medical field, since patient nonadherence can be described and analyzed as a case of weakness of will. ${ }^{12}$

\section{Failure of will in chronic diseases: empirical data}

A study of medical doctors in Pakistan showed that the majority of nonsmokers thought that individual will represents the most important force enabling them not to smoke. ${ }^{13}$ The two reasons most often given by Canadian women ${ }^{14}$ to explain why they do not exercise while they know that it would be good for their health are the lack of time and the lack of willpower. Similarly in a Spanish study, ${ }^{15}$ the reasons given to have an unhealthy diet were irregular schedules at work, 
lack of willpower, and the fact that the proposed food is not very attractive. An English study showed that those who put forward internal type barriers (I am too busy, I lack willpower, I am lazy) rather than external barriers (transport is too long, I have no money, etc) had significantly less physical activity, ${ }^{16}$ and one patient said before bariatric surgery: "I knew that nothing was going to change unless something stopped me". ${ }^{17}$

It is important to note that these examples, suggesting that some patients may feel that it is difficult to make by themselves the autonomous decision of adopting a health behavior, focus on chronic health problems (smoking, diabetes, obesity), and not on acute conditions. As pointed out by Naik et al, who discussed in detail the very concept of autonomy, the exercise of the patient's autonomy in the management of chronic diseases does not include only the usual decisional autonomy (eg, I decide the type of treatment, chemotherapy, or radiotherapy) but should be expanded to include autonomous execution of an agreed upon treatment plan: in acute care, the patient authorizes and the clinical team executes a plan of care, while in chronic care, the patient authorizes and then plays an essential role in executing the plan of care. ${ }^{18}$

\section{Why the exercise of patient's autonomy is not always possible}

Paraphrasing a famous aphorism, one is tempted to say that all can be autonomous some of the time, some can be autonomous all the time, but none can be autonomous all the time. Therapeutic choices of patients are like any decision: they are caused by mental states composed of knowledge and skills, but also of beliefs, emotions, and more or less contradictory desires. This conflict between opposite desires can explain in part nonadherence, which can be seen as the manifestation, in health care, of the weakness of will (incontinence, or akrasia), which earlier challenged Aristotle:

Socrates was entirely opposed to the view in question, holding that there is no such thing as incontinence; no one, he said, when he judges acts against what he judges best - people act so only by reason of ignorance. Now this view plainly contradicts the apparent facts, and we must inquire about what happens to such a man; if he acts by reason of ignorance, what is the manner of his ignorance ${ }^{19}$

Actually, this is not a matter of "ignorance": "I know, but it is stronger than me, I cannot help myself," says this patient who cannot avoid smoking, dietary distortions, and other such activities. It is important to recognize that many obstacles are opposed to adherence: for example, the expected reward (the preservation of health) is quite remote and abstract, whereas the reward of nonadherence in general is immediate and concrete. ${ }^{12}$

In addition, in a chronic disease, one has to consider the future: to protect a remote person, the old person that I will be, whom I have difficulties to imagine. As noted by the philosopher, Derek Parfit,

... my concern for my future may correspond to the degree of connectedness between me now and myself in the future. Since connectedness is nearly always weaker over longer periods, I can rationally care less about my further future..$^{20}$

In fact, the concept of care implies that one is concerned with one's future, as noted by the philosopher, Harry Frankfurt, considering the relationship between the concepts of care and importance. This is the difference between caring about something and merely wanting something: I may want to eat an ice cream; my desire of the ice cream does not involve my future: I do not consider it so important. By contrast, "the outlook of a person who cares about something is inherently prospective; that is, he necessarily considers himself as having a future". ${ }^{21}$

Incidentally, these remarks may explain why nonadherence in chronic diseases is more frequent in younger patients. $^{22-26}$ They are consistent with the findings of two studies showing that when compared to nonsmoking women, smokers have a shorter temporal horizon, ${ }^{27}$ and that women who favor the future more than the present are generally those women who request breast cancer screening. ${ }^{28}$ They may help understand the association between social deprivation and nonadherence. ${ }^{29}$

Thus, patients often express the view that there are two people in them, the one who would like to take care of herself, and the one who does not care. The person who decides is me, now, hic et nunc, but this me at the time of choice is divided. This division of mind may represent an impediment to the exercise of autonomy: among these multiple me's who may have conflicting desires at the moment of the choice, who makes the decision?

We mentioned previously that therapeutic choices are caused by different mental states: in addition to desires, the lack of appropriate knowledge and skills, the presence of wrong beliefs (eg, denial of the disease), and last but not least, emotions may also jeopardize the exercise of autonomy. For instance, our beliefs are not under the control of our volition ${ }^{30}$ and Christine Tappolet showed the role of emotions in the genesis of the weakness of will. ${ }^{31}$ 
In summary, this analysis leads us to follow Merle Spriggs $^{32}$ who distinguished two conceptions of patient's autonomy: on one hand, a Kantian conception, metaphysical, which essentially considers the autonomy of the person in general and can be considered as the foundation of a "principled" autonomy, and on the other hand, a psychological conception of autonomy deriving from the work of John Stuart Mill, ${ }^{33}$ where autonomy is defined as the capacity of making choices, based on the values and the preferences of the individual. This psychological account of autonomy indicates clearly that the exercise of autonomy is not always possible.

\section{How care can meet the pitfall of pure paternalism: arriving to a paradox}

Where it is not possible, how, in the context of the autonomy principle, can someone (a HCP) decide on what is good (a treatment) for someone else (a patient) without falling into paternalism or manipulation?

\section{Etymology of care}

The word "care" comes from the old English word, caru, cearu: care, concern, anxiety, sorrow, grief, trouble; this old English word was derived from the proto-Germanic word, *karō: care, sorrow, cry; that proto-Germanic word, in turn, came from the proto-Indo-European word, *gāar-, *gÀr-: voice, exclamation. Thus, etymologically at least, care seems to be the answer to a cry: is not care the innate answer of the mother, when she hears, for the first time, the cry of her child? We saw above that the Frankfurtian notions of care and importance are linked and that the notion of care encompasses the notion of future: when the mother takes care of her child, the future of her child is important for her, and her child is her future.

\section{Health care as an answer to a cry: introducing the notion of sympathy}

Philosopher Stephen Darwall, in his book "Welfare and Rational Care", ${ }^{34}$ considers the example of a patient in a deep depression:

... empathizing with this person, we imagine how things feel to her, for example, how worthless she feels. Empathy is seeing and feeling things as we imagine her to see and feel them. When, however, we view her situation with sympathy (a sympathy she perhaps cannot muster for herself), she and her welfare seem important, not worthless.
Sympathy for someone, on the other hand, is felt not as from her standpoint but as from the perspective of someone (anyone) caring for her. ${ }^{34}$

Empathy consists of imagining what is good from the point of view of the person, while sympathy is imagining what is good for that person. Darwall ${ }^{34}$ also considers the example taken from the Chinese philosopher, Mencius: seeing a child on the verge of falling into a well, one is concerned for his safety, for him. Sympathy for the child is a way of caring for (and about) him. Darwall proposes therefore the following definition of sympathy: It is a feeling or emotion that: 1) responds to some apparent obstacle to an individual's welfare; 2) has that individual himself as object; 3 ) involves concern for him, and thus for his welfare, for his sake. ${ }^{34}$

According to this definition of sympathy, an individual's welfare, that is, what is important for her, is defined not by this person herself but by "someone (anyone) caring for her". Anyone caring for her, because she cares for her, is entitled to define what is good for her, thereby ensuring her welfare. However, if we apply this relationship between sympathy and care to the specific case of health care, we run into the pitfall of paternalism. Paradoxically, care and autonomy seem to become antinomic, and this antinomy may even go further. Darwall $^{34}$ shows that this difference between empathy and sympathy is analogous to the difference between respect and care:

The contrast between respect and care reconfirms the distinction between what is or seems good from someone's viewpoint [empathy] and what is for his good or welfare [sympathy]. Treating another's point of view as normative is a form of respect. Taking a person's welfare as normative is a form of care. The respect we demand from others calls for empathy. The care we hope for, from some at least, is sympathy. ${ }^{34}$

Thus, if this philosophical analysis of empathy and sympathy, of respect and care, is applied to the medical field of health care, we arrive at a paradox: not only does care and autonomy seem to be antinomic; the same seems to hold true for care and respect.

\section{Solving the paradox Four models of the patient- physician relationship}

Figure 2 represents the four models of the patient-physician relationship, as proposed by Emanuel and Emanuel..$^{35}$ The paternalistic model is the traditional one: the physician 
decides what the most appropriate treatment is. She gives selective information to the patient to obtain the patient's consent. In the informative model, the physician's responsibility is to give the patient all the relevant information concerning the diagnosis and the different therapeutic options, without hiding from her the possible uncertainties, so that the patient can choose a therapeutic option. In the interpretative model, the goal of the therapeutic relationship is not only to give the patient information but also to help her elucidate her preferences, as they may not be explicit, and then to help her to act according to her preferences by explaining which therapeutic option is the most appropriate given those preferences as revealed during the therapeutic interaction. Finally, in the deliberative model, not only does the physician indicate what the patient could do, but knowing the patient and wishing what is best, the physician indicates what the patient should do, what decision regarding medical therapy would be admirable. Here, the patient is empowered not simply to follow unexamined preferences or examined values, but to consider through dialogue alternative health related values; in other words, to deliberate on the differences between her own and her physician's preferences.

In Figure 2, I purposely represented the four models in a circular form. One may fear that the deliberative model is actually nothing but disguised paternalism: do they not have the same goal, that is, to lead the patient to do what the physicians want her to do?

\section{Philosophical conception of autonomy as a reflexive activity of the mind}

During the years that saw the birth of contemporary bioethics, philosophical works agreed on the importance of an individual's reflexive activity concerning her own desires and on the use of the concept of value for a psychological definition of autonomy. Thus, David Lewis, in his article, "Dispositional Theories of Values", ${ }^{36}$ suggested in 1989 that

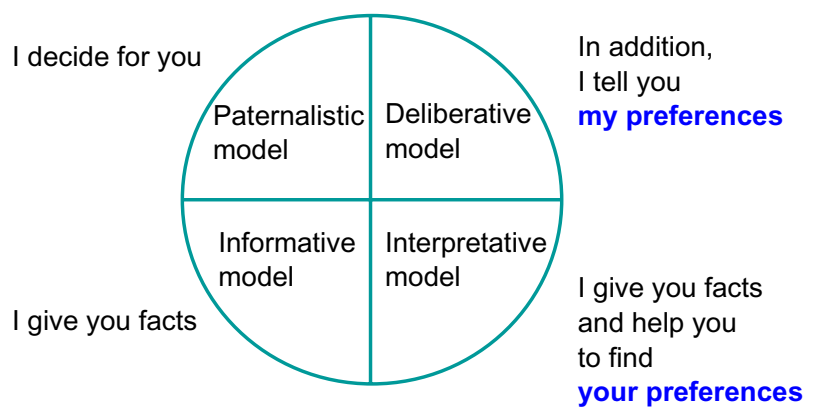

Figure 2 Four models of the physician-patient relationship, definitions from Emanuel and Emanuel. ${ }^{35}$ the value that one attributes to something and which will make us give a preference to it can be understood as wanting to want this thing: a smoker may want to smoke a cigarette and at the same time not ascribe any value to her addiction and actually want to quit smoking. It is only if she wants to want to smoke can we say that she places value on smoking. Thus, the definition of preference encompasses that of value and implies the existence of second order desires: wanting to want, ie, a reflexive activity of the mind.

Gerald Dworkin, in "The Theory and Practice of Autonomy", ${ }^{37}$ published in 1988, used this reflexive activity to define the autonomous person: autonomy is a second order capacity to reflect critically upon one's first order preferences and desires. In addition, autonomy is the ability to either accept one's preferences, desires, and wishes or try to change them in light of higher order preferences and values. ${ }^{37}$

Not only does this capacity define the autonomous person, it also defines the very concept of a person. In 1971, Harry Frankfurt in his article, "Free Will and the Concept of a Person", ${ }^{38}$ proposed that to be a person, and not simply the puppet of brute desires (what he calls a wanton), is to have the capacity for reflective self-evaluation that is manifested in the formation of second order desires, which supersede first order desires. What is more, I am a person if it is important to me that my will is free, ie, that I am capable not only of wanting something and doing what I want, but am able to do what I want to want. ${ }^{38}$

\section{Solving the paradox of autonomy and care: speaking to a person rather than to a patient}

These definitions that link the concepts of preference, person, and autonomy to the notion of reflexivity make it possible to solve what we called herein the paradox of autonomy: the antinomy between care and autonomy, between care and respect. This apparent antinomy disappears if and only if I consider that when I, as a HCP, give my preferences, I do not speak to a "patient"; rather, I speak to an autonomous person, ie, someone who, according to Frankfurt and Dworkin, ${ }^{37,38}$ is able to deliberate, and to change her mind: I do it at the end of an ethical pathway, which goes from the informative to the interpretative model (role of empathy, helping the patient to elucidate her references), and next to the deliberative model, ie, sympathy introducing the HCP's preferences. Under this condition, care is therefore neither paternalism nor manipulation: the deliberative model differs from the paternalistic model because it can be reached only at the end of this pathway. 
Incidentally, it is important to consider again the difference between the autonomy of the person in general, and the autonomous decision concerning for instance the specific action of smoking. The patient as a person may perfectly retain her autonomy while accepting to enter into a discussion between her own, and the HCP's preferences on a specific issue, for instance smoking. Furthermore, the patient remains an autonomous person if she freely decides to delegate her autonomy to her HCP, saying: please, decide, you are the doctor.

This attitude was recognized by Alfred Tauber:

How is autonomy to be exercised if a patient becomes "preoccupied" and unable to take part in making medical decision? Though such persons run the risks associated with paternalism, they generally exercise their autonomy by distinguishing (per the Frankfurt-Dworkin model) higher and lower decision making and so avoid the burden of executing lower choices they feel incapable of making. Patients delegate such decisions, because they reasonably believe that physicians are more capable of assessing technical choices for them. ${ }^{39}$

\section{An ethical definition of patient education}

I suggest that the role of patient education is to pave this ethical pathway that links the three models (Figure 3). This ethical role of patient education may actually represent its very definition. Introducing patient education on this figure shows that in the same vein that there is no antinomy between autonomy and care, there is no antinomy between autonomy and patient education, again if the clinician adopts a definition of patient education which recognizes the fact that it is addressed to an "autonomous person" (according to the Frankfurt-Dworkin definition), and not to a "patient".

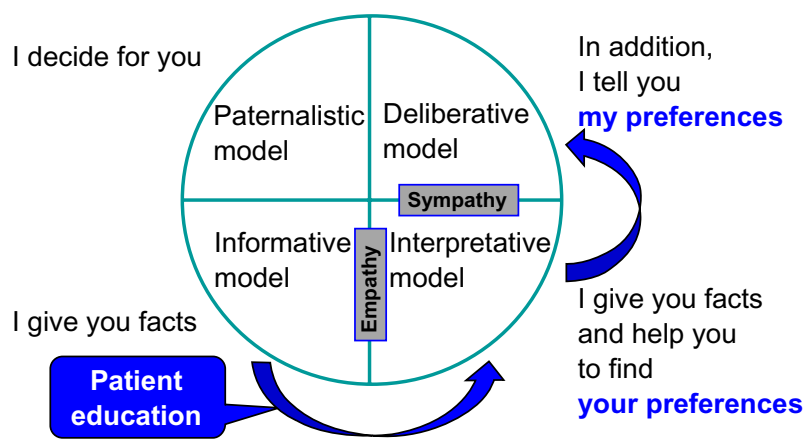

Figure 3 A model of care in chronic diseases: patient education as an ethical pathway. A definition of patient education: patient education is the empowering process that in chronic care not only provides information to the patients but also leads them to an interpretation of their own preferences and a deliberation between their, and the HCP's, preferences.
One may even go further: there is also no more antinomy between patient education and respect, and on the contrary, an absence of patient education would be synonymous with absence of respect, since it would mean that the HCP does not consider the patient able to change her mind. Patient education is respect, it is the same thing. Thus, on an ethical point of view, it appears therefore that the practice of patient education is not only possible, but is also necessary.

It was suggested above that all can be autonomous some of the time, some can be autonomous all time, but none can be autonomous all the time. Actually, all the time, or sometimes, some persons may wish a paternalistic physician-patient relationship. How should clinicians respond to this patient preference? I suggest that as often as possible, they should adopt an attitude using the ethical pathway described above: explaining that there are different alternatives if any, asking for the patient's preference (empathy) and giving their own preference (sympathy) for proposing a given therapy. This again suggests that patient education should at least, at a minima, be present in the process of care. This is why, according to the World Health Organization, patient education may indeed be a necessary part of care: ${ }^{40}$ not only for technical, but also for ethical reasons.

Incidentally, we recently showed in an empirical study ${ }^{41}$ in obese type 2 diabetic patients the existence of an association between patient adherence to medication and the fact that patients declared that they fasten their seatbelt when they are seated in the back of a car, and we interpreted this association as a room for obedience in patient adherence. We proposed that a role for patient education was to replace this passive reason to be adherent to therapy by an active conscious choice. ${ }^{41}$

\section{Patient autonomy and trust}

According to Shinebourne and Bush, delegating autonomy may be

... what many patients do wish for: that is to have medical care based on mutual trust between doctor and patient with the assumption that as a member of a profession the doctor will make choices in the best interests of the patient. ${ }^{42}$

The presence in this quotation of the word "trust" is not surprising: in this analysis, we suggested that the ethical pathway ends up with a discussion of preferences. As defined above, a preference is the value a person gives to one over various alternatives and one can better agree on values within a context of trust. An empirical study ${ }^{43}$ yielded results consistent with the concepts discussed herein: it showed that trust was the variable most strongly associated with patients' 
satisfaction with their physician, and that the physicians' comprehensive ("whole person") knowledge of patients and patients' trust in their physician were the variables most strongly associated with adherence, patients with higher trust in their physician being significantly more likely to report engaging in eight recommended health behaviors, including exercise, smoking cessation, and safe sexual practices.

Furthermore, a study ${ }^{44}$ suggested the following physician behaviors as the factors that determine the trust that a patient has in her HCP. Several qualities of the physician seem to be involved:

The attribute of technical competency is fairly self-evident, although the physician behavior used by patients to judge technical competency may be quite different from behavior that would be judged by a colleague. Interpersonal competency refers primarily to communication and relationshipbuilding skills - listening, understanding, providing complete and honest information, and expressing caring. The third domain, agency, is more specific to trust. It refers to acting in the patient's interest - for example, putting the patient's welfare ahead of costs or other considerations. An additional domain, confidentiality, is rarely mentioned by patients and is more weakly associated with the concept of trust as defined by the other domains. ${ }^{44}$

The emphasis on empathy and communication suggests a link between trust and the ability of the HCP to engage in patient education.

\section{Discussion}

The proposed model of chronic care involving patient education (Figure 3) may well represent an ideal situation. One should not assume, therefore, that patients must proceed through the cycle, even if they do not want to, or judge it (rationally or irrationally) to be not in their best interest to engage in that cascade. They remain free of deciding for one of the four models. The authors of a study carried out in patients with cardiac failure, showing the heterogeneousness of the behavior of the patients about their desire to participate in medical decisions, recommended simply asking the patients what they wish in this respect, rather than to refer to a particular model..$^{45}$ If they do not know, medical art may mean being capable of choosing, at the appropriate moment, between various models of the therapeutic relationship.

Concerning the involvement of trust in the patientphysician relationship, the overall argument seems to assume that a) trust can be established between the HCP and the patient, b) the patient decides that the trust should be established, and c) is willing to work towards establishing such a trust. This may not happen: the patient could just as easily decide not to allow the trust to be established, and mandating that trust must be established would be an obvious violation of the patient's autonomy. This points out the importance of the final remark of Shinebourne in his chapter defending a place for paternalism in the patient-physician relationship: "The doctor must in turn realize that trust (of doctor by patient) has to be earned, gained, must not be abused and should not be assumed - indeed why should it be". ${ }^{42}$

In the model proposed in Figure 3, trust plays its most important role in the last step comparing the patient's and HCP's preferences (ie, from the interpretative to the deliberative model). Again, the patient remains free to opt for the interpretative model, or to engage or not in the whole cascade, ie, in patient education. However, the role of trust is also important in the informative model, where the patients has to believe the information given by the physician (providing information is a part of patient education). Indeed, the formation of a new durable belief (for instance, "I believe that it is good for my health to exercise") is the result of several assessments: of probability, taking into account everything I know; of plausibility, examining whether I can explain the phenomenon that is the object of the belief; but also of credibility, based on the evaluation of the reliability of the sources at my disposal. ${ }^{46}$

This analysis seems therefore to suggest that trust must be somewhat present in a sound patient-physician relationship (even if, as discussed above, the physician is obviously in no way entitled to impose it). Actually, the whole medical practice supposes the existence of trust: how can the patient accept to answer the physician questions, the clinical examination of her body, and the proposed therapy? We saw that a relationship of trust cannot be assumed and has to be earned and gained. In addition, the physician, afterwards, has to demonstrate that he/she is trustworthy. Actually, this is a condition of patient's trust in her doctor, according to the concept of "encapsulated interests" developed by Russel Hardin:

I trust you because I think it is your interest to take my interests in the relevant matter seriously in the following sense. You value the continuation of our relationship and you therefore have your own interest in taking my interests into account. That is, you encapsulate my interests in your own interests. ${ }^{47}$

This importance of trust in the patient-physician relationship also points out the obligation for physicians to reject 


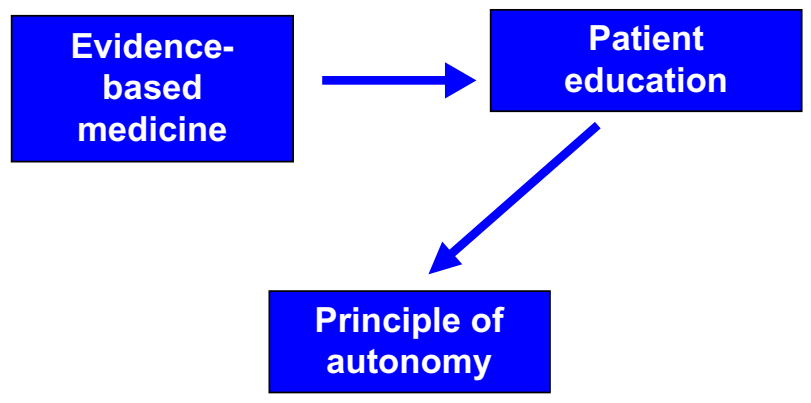

Figure 4 Solving the paradox: patient education promotes patient's autonomy.

deception when providing information to the patients. Onora O'Neill in "Autonomy and Trust in Bioethics" shows how this obligation has

... many implications: It will be expressed in refraining from lying, from false promising, from promise breaking, from misrepresentation, from manipulation, from theft, from fraud, from corruption, from passing off, from impersonation, from perjury, from forgery, from plagiarism, and from many other ways of misleading. More positively, it will be expressed through truthful communication, through care not to mislead, through avoidance of exaggeration, through simplicity and explicitness, through honesty in dealing with others, in a word, through trustworthiness. ${ }^{48}$

\section{Conclusion}

The simultaneous "inventions" of patient education and patient autonomy in contemporary biomedicine may seem at first glance contradictory, since on the one hand the doctor may wish to apply the principle of beneficence and teach the patient how to benefit from the medical progress evaluated in the framework of evidence based medicine, and on the other hand has to respect the patient's autonomy. In the same period, the concept of patient nonadherence (formerly called noncompliance, this passive word illustrating the absence by that time of concern from the medical community for autonomy!) emerged as a major problem jeopardizing the efficiency of care.

In this article, I have shown that if the physician only obeys to the principle of beneficence, an attitude referred to herein as sympathy according to Darwall' $\mathrm{s}^{34}$ definition, this behavior can lead to the paradoxical conclusion that care becomes antinomic with the respect of patient's autonomy, and even with the mere patient's respect. I proposed as a solution to this paradox that, in a Frankfurt-Dworkin definition of the autonomous person, ${ }^{37,38}$ care is proposed, and explained to an individual able to evaluate her preferences and eventually to change her mind and to accept the physician's proposal. This deliberation occurs at the end of an ethical pathway, linking in a stepwise escalade the four models of the patientphysician relationship described by Emanuel and Emanuel, ${ }^{35}$ where the physician first gives the fact (information), helps the patient to elucidate her own preferences (interpretation), and finally gives her the opportunity to choose between different alternatives (deliberation). I propose that a major role of patient education is to pave this ethical pathway, which makes the difference between the deliberative, and the paternalistic, model.

In addition, patient education, by giving the patient the opportunity to choose between her own, and her physician's, preferences, provides her the opportunity to exercise her autonomy. Figure 4 therefore modifies Figure 1 by suggesting that the conflict between patient education and the principle of autonomy was only apparent. Patient education may help to empower the weak-willed patient who has difficulty forming healthy preferences in the first place by showing her that there are alternatives, and that as an autonomous person, she has the possibility "to change her mind" and how to apply this change. I suggest that this may help to proceed from the precontemplation to the contemplation stage of the Prochaska's model. ${ }^{49}$ Of course, this does not mean that the patient will proceed to the next stages of the model. ${ }^{50}$

As shown above the difficulty of projection into the future represents an obstacle to patient adherence to long term therapies. If patient education considers the patient as a person, having her own history, not only past, but also future, it may play a major role in helping the patient to overcome this obstacle by showing her how the therapeutic plan can take into account her projects.

This article also discussed the place of trust, pointing out that a determinant of trust is the clarity of the explanations provided by the HCP. This provides a link between trust and patient education. It is important to note that patient education's influence is largely based on a cognitive process, which works at the level of our "system 2" of decision making, which is reflective, conscious, controlled, analytic, slow, and cognitively demanding, rather than on our "system 1", which is unconscious, uncontrolled, heuristic, fast, and cognitively parsimonious. ${ }^{51-53}$ This distinguishes patient education from a mere manipulation, which would act on system 1 .

I suggest that what may be morally acceptable ${ }^{53}$ in the context of "nudge" - influencing the behaviors of populations by acting at the level of system 1 , which is efficacious precisely because people do not deliberate on their choices, remaining actually free to behave differently, ${ }^{52}$ would not be 
acceptable in the case of an individual patient, even if it is aimed at improving the patient's welfare (principle of beneficence), because this would violate the fact that the patient is a person, ie, a being endowed with a reflexive mind.

\section{Acknowledgment}

These concepts were presented in part in a keynote lecture given at the 18th Annual Conference of the Foundation of European Nurses in Diabetes (FEND) in Barcelona, Spain, September 20, 2013.

\section{Disclosure}

The author has no conflict of interest to disclose within the framework of this article.

\section{References}

1. Beauchamp T, Childress J. Principles of Biomedical Ethics. 1st ed. Oxford: Oxford University Press; 1979.

2. Miller LV, Goldstein J. More efficient care of diabetic patients in a county-hospital setting. N Engl J Med. 1972;286:1388-1391.

3. Cochrane AL. Effectiveness and Efficiency. Random Reflections on Health Services. London: Nuffield Provincial Hospitals Trust, 1972.

4. The Diabetes Control and Complications Trial Research Group. The effect of intensive treatment of diabetes on the development and progression of long-term complications in insulin-dependent diabetes mellitus. N Engl J Med. 1993;329:977-986.

5. McCrimmon RJ, Frier BM. Hypoglycaemia, the most feared complication of insulin therapy. Diabetes Metab. 1994;20:503-512.

6. Thompson CJ, Cummings JF, Chalmers J, Gould C, Newton RW. How have patients reacted to the implications of the DCCT? Diabetes Care. 1996;19:876-879.

7. Haynes RB, Taylor DW, Sackett DL, editors. Compliance in Health Care. Baltimore: John Hopkins University Press; 1979.

8. Schneewind JB. The Invention of Autonomy. Cambridge: Cambridge University Press; 1998.

9. Kant I. Critique of Practical Reason, First Part, Book 1, Chap. 1, Problem II, Remark. 1788.

10. Saint Paul, Romans 7:15-25.

11. Watson G. Skepticism about weakness of will. Philosophical Review. 1977;86:316-339, 327.

12. Reach G. A novel conceptual framework for understanding adherence to long term therapies. Patient Prefer Adherence. 2008;2:7-19.

13. Memon SB, Memon AM. Why physicians and lay people smoke and how can it be reduced? J Pak Med Assoc. 1999;49:2-4.

14. Olmsted MP, McFarlane T. Body weight and body image. BMC Womens Health. 2004;4 Suppl 1:S5.

15. Lopez-Azpiazu I, Martinez-Gonzalez MA, Kearney J, Gibney M, Martinez JA. Perceived barriers of, and benefits to, healthy eating reported by a Spanish national sample. Public Health Nutr. 1999;2: 209-215.

16. Ziebland S, Thorogood M, Yudkin P, Jones L, Coulter A. Lack of willpower or lack of wherewithal? 'Internal' and 'external' barriers to changing diet and exercise in a three year follow-up of participants in a health check. Soc Sci Med. 1998;46:461-465.

17. Ogden J, Clementi C, Aylwin S. The impact of obesity surgery and the paradox of control: a qualitative study. Psychol Health. 2006;21:273-293.

18. Naik AD, Dyer CB, Kunik ME, McCullough LB. Patient autonomy for the management of chronic conditions: a two-component re-conceptualization. Am J Bioeth. 2009;9:23-30.

19. Aristotle. Nicomachaen Ethics, Book VII, 2, 1-2.
20. Parfit D. Reasons and Persons. Oxford: Clarendon Press; 1984: 313-314.

21. Frankfurt HG. The Importance of What We Care About. Cambridge: Cambridge University Press; 1988.

22. Briesacher BA, Andrade SE, Fouayzi H, Chan KA. Comparison of drug adherence rates among patients with seven different medical conditions. Pharmacotherapy. 2008;28:437-443.

23. Lee R, Taira DA. Adherence to oral hypoglycemic agents in Hawaii. Prev Chronic Dis. 2005;2:A09.

24. Cooke CE, Lee HY, Tong YP, Haines ST. Persistence with injectable antidiabetic agents in members with type 2 diabetes in a commercial managed care organization. Curr Med Res Opin. 2010;26(1): 231-238.

25. Tiv M, Viel JF, Mauny F, Eschwège E, et al. Medication adherence in type 2 diabetes: The ENTRED Study 2007, a French Population-Based Study. PLoS One. 2012;7(3):e32412.

26. Reach G, Le Pautremat V, Gupta S. The determinants and consequences of insulin initiation for type 2 diabetes in France: analysis of the National Health and Wellness Survey. Patient Prefer Adherence. 2013;7:1007-1023.

27. Jones BA, Landes RD, Yi R, Bickel WK. Temporal horizon: modulation by smoking status and gender. Drug Alcohol Depend. 2009;104(Suppl 1):S87-S93.

28. Gurmankin Levy A, Micco E, Putt M, Armstrong K. Value for the future and breast cancer-preventive health behaviour. Cancer Epidemiol Biomarkers Prev. 2006;15:955-960.

29. Wamala S, Merlo J, Bostrom G, Hogstedt C, Agren G. Socioeconomic disadvantage and primary non-adherence with medication in Sweden. Int J Qual Health Care. 2007;19:134-140.

30. Engel P. Introduction: the varieties of belief and acceptance. In: Engel P, editor. Believing and Accepting, Philosophical Studies Series. Dordrecht: Kluwer Academic Publishers; 2000:1-30.

31. Tappolet C. Emotions and the intelligibility of akratic actions. In: Stroud S, Tappolet C, editors. Weakness of Will and Practical Irrationality. Oxford: Clarendon Press; 2003:97-120.

32. Spriggs M. Autonomy and Patients' Decisions. Lanham: Lexington Books; 2005.

33. Mill JS. On Liberty and Considerations on Representative Government. RB McCallum ed; Oxford: Basil Blackwell 1948.

34. Darwall S. Welfare and Rational Care. Princeton Monographs in Philosophy. Princeton: Princeton University Press; 2002.

35. Emanuel EJ, Emanuel LL. Four models of the physician-patient relationship. JAMA. 1992;267:2221-2226.

36. Lewis D. Dispositional theories of values. Proceedings of the Aristotelian Society. 1989;63:113-137.

37. Dworkin G. The Theory and Practice of Autonomy. Cambridge: Cambridge University Press; 1988.

38. Frankfurt HG. Freedom of the will and the concept of a person. J Philos. 1971;68:5-20.

39. Tauber AI. Patient Autonomy and the Ethics of Responsibility. Cambridge: MIT Press; 2005:142.

40. World Health Organisation. Therapeutic Patient Education: Continuing education programmes for health care providers in the field of prevention of chronic diseases. WHO Copenhagen, 1998.

41. Reach G. Obedience and motivation as mechanisms for adherence to medication: a study in obese type 2 diabetic patients. Patient Prefer Adherence. 2011;5:523-531.

42. Shinebourne EA, Bush A. For paternalism in the doctor-patient relationship. In: Gillon R, Lloyd A, editors. Principles of Health Care Ethics. New York: John Wiley \& Sons; 1994:407.

43. Safran DG, Taira DA, Rogers WH, Kosinski M, Ware JE, Tarlov AR. Linking primary care performance to outcomes of care. J Fam Pract. 1998;47:213-220.

44. Thom DH, Hall MA, PawlsonLG. Measuring patients' trust in physicians when assessing quality of care. Health Aff. 2004;23: 124-132. 
45. Clarke G, Hall RT, Rosencrance G. Physician-patient relations: no more models. Am J Bioeth. 2004;4:W16-W19.

46. Fridja NH, Mesquita B. Beliefs through emotions. In: Fridja NH, Manstead ASR, Bem S, editors. Emotions and Beliefs. How Feelings Influence Thoughts. Cambridge: Cambridge University Press; 2000:69.

47. Hardin R. Trust and Trustworthiness. New York: Russel Sage Foundation; 2004.

48. O'Neill O. Autonomy and Trust in Bioethics. Cambridge: Cambridge University Press; 2002:98.

49. Prochaska JO, DiClemente CC. Stages and processes of self-change of smoking: toward an integrative model of change. J Consult Clin Psychol. 1983;51:390-395.
50. Reach G. Obstacles to patient education in chronic diseases: a transtheoretical analysis. Patient Educ Couns. 2009;7:192-196.

51. Kahneman D. Thinking, Fast and Slow. Penguin (UK): Allen Lane; 2011.

52. Thaler RH, Sunstein CR. Nudge: Improving Decisions about Health, Wealth, and Happiness. New Haven: Yale University Press; 2008.

53. Saghai Y. Salvaging the concept of nudge. J Med Ethics. 2013;39: 487-493.

\section{Publish your work in this journal}

Patient Preference and Adherence is an international, peer-reviewed, open access journal focusing on the growing importance of patient preference and adherence throughout the therapeutic continuum. Patient satisfaction, acceptability, quality of life, compliance, persistence and their role in developing new therapeutic modalities and compounds to optimize clinical outcomes for existing disease states are major areas of interest. This journal has been accepted for indexing on PubMed Central. The manuscript management system is completely online and includes a very quick and fair peer-review system. Visit http://www.dovepress.com/ testimonials.php to read real quotes from published authors. 